\title{
HERNANDEZ ANDREU Y LA CRISIS DE 1929
}

JOSEPH HARRISON

Universidad de Manchester

En marcado contraste con las experiencias de Estados Unidos, Alemania - Gran Bretaña, hay numerosos indicios de la superficialidad de la recesión económica española en los años treinta. Recientemente, la revisión de las estimaciones de la Renta Nacional, efectuada por Julio Alcaide, mostró la sostenida tendencia al alza de la economía española entre 1929 y 1935, excepto por pequeños descensos en 1930, 1933 y 1935. En conjunto, según las cifras proporcionadas por Alcaide, la Renta Nacional, en pesetas constantes de 1964, creció en un 9,7 por 100 en estos siete años. Sin embargo, como Juan Hernández Andreu nos recuerda en su último libro *, el número de parados al sus de los Pirineos se elevó hasta alcanzar la cifra de 801.322 en junio de 1936, por lo que no se puede poner en duda que al Gobierno del Frente Popular le rue tan mal en este aspecto como al de Hoover en sus últimos meses, a la República de Weimar o al segundo Gobierno laborista de MacDonald, en Gran Bretaña. Si aceptamos los datos de la Sociedad de Naciones sobre la producción industrial, los índices mundiales (excluyendo a la Unión Soviética) cayeron en un 37 por 100, los de Norteamérica en un 45 por 100 y los de la Europa no comunista en un 29 por 100, entre 1929 y 1932. España, por su parte, alcanzó el punto más bajo de su producción industrial en 1933, con un 15 por 100 por debajo del nivel de 1929.

No obstante, existe la creencia generalizada entre los historiadores de que los sucesivos Gobiernos de Primo de Rivera, Berenguer, Aznar y de la Segunda República fueron sacudidos por una diversidad de perturbaciones económicas, de origen tanto interno como externo. Entre estas últimas, mencionadas frecuentemente como factores causales de la menor profundidad de la depresión española, está la brusca caída en el comercio mundial, consecuencia de una nueva ola de proteccionismo, ilustrada por el arancel Smoot-Hawley de 1930, en Estados Unidos, y por la Ley de Aranceles Proteccionistas de 1932, en Gran Bretaña. Según las estadísticas oficiales del comercio exterior

* Juan Hernández Andreu, España y la crisis de 1929, Madrid, Espasa-Calpe, 1986, 260 pp. 
español, cuya fiabilidad fue puesta en tela de juicio por Valentín Andrés Alvarez hace más de cuatro décadas, las importaciones bajaron hasta un 52 por 100 en 1931, mientras que, en el mismo año, las exportaciones cayeron en un 40 por 100 de su valor de 1930 en términos monetarios. Hernández Andreu, basándose en un artículo de Antonio Tena, publicado en esta revista («Una reconstrucción del comercio exterior español, 1914-35: la rectificación de las estadísticas oficiales», Revista dE Historia Económica, 1985), llega a decir que el declive del comercio exterior español fue tan acusado como el de las grandes naciones capitalistas. Al decir esto, rechaza el trabajo de reelaboración de Jordi Palafox de las estadísticas comerciales de los principales países que comerciaban con España (Gran Bretaña, Francia y Estados Unidos), que son mucho menos pesimistas ( $\alpha \mathrm{La}$ crisis de los años 30: sus orígenes», Papeles de Economía Española, 1980). Sin embargo, cualquiera que sea la magnitud exacta de la caída de las ventas en el extranjero a principios de los años treinta, la escasa dependencia española del comercio exterior aseguró que el declive de las exportaciones no fuera una causa de la decadencia económica nacional, a pesar de la incidencia que esto tuvo en el País Valenciano tras el acuerdo de Ottawa de 1932 entre Gran Bretaña y los productores agrícolas de la Commonwealth.

Aparte del comercio exterior, tres variables externas adicionales, como son la inmigración, la disminución de las remesas de los emigrantes y la caída de las inversiones extranjeras, desempeñaron un papel importante en la depresión económica española de los años treinta. Ramón Tamames, en su libro sobre la República y la era de Franco, ha destacado el hecho de que España, anteriormente exportador neto de mano de obra agrícola, en especial a Latinoamérica, vio desaparecer esta válvula de seguridad de la noche a la mañana, cuando las naciones receptoras adoptaron una política de puertas cerradas respecto a los emigrantes del Viejo Mundo. Tamames calcula que, entre 1931 y 1934, la inmigración neta desde los distintos puntos del hemisferio totalizó 106.243 personas, lo que hizo aumentar la masa de parados. No obstante, como señala Jordi Nadal, el componente principal del desempleo durante este período fue el paro estructural, causado no tanto por la vuelta de los emigrantes como por una caída previa de la tasa de mortalidad. Por lo que respecta a las remesas de los trabajadores españoles en Latinoamérica, la imposición de prohibiciones y restricciones sobre la repatriación de sus ahorros tuvo un efecto considerable en la balanza de pagos española. Las investigaciones pioneras de Francisco Jáinaga en el Banco de España revelaron que el saldo neto de remesas bajó de 192.300 millones de pesetas en 1932 a 116.800 millones en 1934. Sin embargo, los cálculos de Jáinaga muestran que, a pesar del advenimiento de lo que muchos inversores extranjeros calificaron de República «socialista» comprometida en la realización de reformas 
radicales, el nivel de las inversiones extranjeras en España se mantuvo en los años de los que poseemos datos, a excepción de una caída en 1933.

¿Hasta qué punto creyeron los contemporáneos que la depresión mundial había influido en la Península? Antes de 1933, al menos, se pensaba que la mayor crisis jamás experimentada por el sistema capitalista había dejado de lado a España. Los observadores nacionales continuaron viendo el comportamiento de la economía con mucho optimismo. La mayoría de ellos consideraba que España no había sido tocada por la depresión. Si se lee la prensa financiera de Madrid del bienio reformista parece que, prácticamente, el único problema que afectaba a la economía española era el supuesto revolucionarismo infantil y el analfabetismo económico de los gobernantes. Destacados hombres de negocios catalanes, entre los que estaba Juan Ventosa -el último ministro de Hacienda de la extinta monarquia-, afirmaban que la crisis internacional había tenido un efecto mínimo en Cataluña. De hecho, el sector principal de la región, la industria textil del algodón, disfrutó de un breve período de prosperidad durante un par de años después de 1931, que siguieron a tres décadas de profundo pesimismo. Para Ventosa, el factor fundamental fue la brusca caída del precio del algodón en los mercados mundiales. Otros han elogiado el esfuerzo de Largo Caballero por elevar el poder adquisitivo de la población rural, gracias a los decretos del Gobierno provisional. Es cierto que los industriales vizcaínos acogieron la nueva década con mucho menos entusiasmo. No obstante, se consideraba que la causa de la caída de los beneficios, y del paro en Bilbao y sus alrededores, era de origen interno: por ejemplo, el abandono de los lucrativos contratos de obras públicas del Gobierno de Primo de Rivera después de la caída del dictador en 1930. Pocos mencionaban que el crash de Wall Street de 1929, el dramático precursor de la crisis internacional, hubiera tenido algún efecto significativo en el progreso de la economía española. Mientras tanto, el objetivo principal de la política económica del Gobierno provisional era el de intentar paliar los problemas estructurales de la agricultura tradicional, sobre todo, la eterna cuestión del paro en el cinturón latifundista del Sur, exacerbado por la sequía.

Muchos historiadores, entre los que se encuentran Josep Fontana y Jordi Nadal, consideran que los problemas profundamente arraigados de la España rural fueron la causa subyacente del comienzo de la guerra civil. Por otro lado, hace casi dos décadas, el eminente economista Juan Sardá, en la historia oficial del Banco de España, resaltó la importancia de estudiar de cerca la política monetaria restrictiva de la República, en especial la del período de Joaquín Chapaprieta. Confrontados, a partir de 1934, con la repentina revelación de que España se estaba quedando al margen de la limitada recuperación que estaba teniendo lugar en otros paises, los ministros de Hacienda de derechas, adelantándose a sus colegas actuales, siguieron una trayectoria 
deflacionista que suscitó el antagonismo de poderosos grupos de interés, e hizo muy poco para evitar el conflicto.

El famoso informe del Banco de España, Ritmo de la crisis económica española en relación con la mundial, publicado en 1934, describía a la nación española como relativamente aislada del sistema capitalista. Según la opinión de su director de estudios, Olegario Fernández Baños, la crisis económica era puramente superficial. Y, sin embargo, ¿podría ser que hayamos estado equivocados todos estos años? ¿Es posible que observadores informados en los años treinta fueran inconscientes de los cambios producidos en la economía mundial que afectaba sus vidas? Después de todo, esto es lo que los historiadores revisionistas aseguran que ocurrió en Gran Bretaña. Autores como Derek Aldcroft, Harry Richardson, John Stevenson y Chris Cook afirman que, a pesar de la miseria humana descrita por Orwell en su obra El camino de Wigan Pier, por Greenwood en Love on the Dole o de la marcha del hambre de Jarrow de 1936, los años treinta fueron una década de un progreso económico impresionante. Los revisionistas sostienen que una combinación especial de factores, entre los que se encuentran la devaluación de la libra esterlina en 1931, la adopción de una política de dinero barato, el auge de la construcción de viviendas, el desarrollo de las llamadas «nuevas" industrias y el aumento de la renta real de aquellos que tenían la suerte de tener trabajo, fue la responsable de la recuperación económica británica de 1932 a 1937, que en ese momento pasó inadvertida en grandes zonas del sur de Gales, del centro de Escocia y del norte de Inglaterra.

En busca de una interpretación más adecuada, la Economic History Society publicó en los años setenta dos folletos que examinaban el estado de la cuestión: el de Bernard Aldford, Depression and Recovery? British Economic Growth, 1918 -39 (1972), y el de Peter Fearon, The Origins and Nature of the Great Slump, 1929-32 (1979). Por otro lado, en Estados Unidos, Charles Kindleberger escribió una síntesis más detallada de la recesión del período de entreguerras en su libro The World in Depression, 1929-39, publicado en 1973, mientras que Peter Temin rechazó la interpretación monetarista de la depresión sufrida por Estados Unidos propuesta por Friedman y Schwartz en su libro Did Monetary Forces Cause the Great Depression? (1976). Este debate, con una amplia historiografía en inglés, y que tanto animó los seminarios a ambos lados del Atlántico, pasó casi totalmente inadvertido en España. Así, como se afirma en la cubierta del libro de Juan Hernández Andreu, «es ésta la primera obra publicada en España sobre los orígenes y manifestaciones de la crisis de 1929 y la depresión del decenio de 1930 en una perspectiva mundial».

En una serie de publicaciones aparecidas durante más de una década, el profesor Hernández Andreu ha mantenido una línea independiente respecto 
a los historiadores económicos españoles al insistir en la importancia de los factores externos en la depresión económica española del período de entreguerras. La novedad del enfoque actual está en la inclusión de un capítulo introductorio general sobre las consecuencias económicas de la Primera Guerra Mundial. Esta sección, en gran medida de síntesis y que sirve como antecedente a la discusión sobre la Gran Depresión, ocupa un tercio del libro. Es, esencialmente, una exposición ajustada y bien escrita del consenso liberal que se ha desarrollado en Estados Unidos, asociado a los nombras de Kindleberger, Temin y Walt Rostow, a quienes el autor elogia ampliamente. Un punto débil de este trabajo se encuentra en el hecho de no mencionar muchas de las investigaciones llevadas a cabo en Europa. Elaborado cuidadosamente, este primer capítulo concede la importancia debida a aquellas variables que desempeñaron un papel fundamental en los acontecimientos mundiales de 1929 a 1933, y a las recuperaciones parciales que tuvieron lugar después. Entre ellas se incluyen los reajustes territoriales postbélicos, las reparaciones y deudas de guerra, la caída de los precios agrícolas (que el autor subraya especialmente), el caos financiero de los años 1925 a 1931, el renacimiento proteccionista, etc. Así, dicho capítulo adopta una especie de modelo amplio para analizar la depresión española. Se hacen frecuentes alusiones a la postura de Kindleberger sobre la importancia de la caída de los precios agrícolas, posiblemente en un intento de legitimar la propia interpretación de Hernández Andreu. La segunda parte del libro consta de cuatro capítulos, de distinta longitud, que tratan de diversos aspectos de la economía española -agricultura, industria, comercio, finanzas, mano de obra- en diferentes etapas del siglo xx. Tal desequilibrio es, en parte, resultado de la manera en que el autor utiliza la obra como vehículo para reproducir materiales sobre el sector eléctrico y la política monetaria, publicados anteriormente en forma de artículo.

En resumen, su tesis principal, repetida varias veces a lo largo del texto, es que, durante la segunda mitad de los años veinte, la agricultura española experimentó una depresión estructural por la tendencia a la baja de los precios, proceso exacerbado después de 1929 por la crisis mundial, que hizo caer los precios de los productos primarios. Al mismo tiempo que sus ingresos se vieron fuertemente reducidos, los agricultores se encontraron con costes de producción cada vez mayores, en parte, por su dependencia de los fertilizantes químicos para mantener los rendimientos. A pesar de los tempranos intentos de sustituir importaciones, la industria química nacional no satisfizo las necesidades de los agricultores. $\mathrm{Y}$ es más, al buscar una mayor protección arancelaria en conjunción con la industria eléctrica, las compañías eléctricas amenazaron con gravar al agricultor todavía más. Así, la demanda inelástica de importaciones de fertilizantes químicos, junto con la depreciación de la peseta en un 40 por 100 en el período de 1928 a 1932, hizo aún más inso- 
portable su situación. Los agricultores protestaron, con Valencia a la cabeza. Mientras tanto, el descenso de la renta agrícola llevó a una contracción de la demanda de productos manufacturados, las nuevas industrias fueron frenadas en su desarrollo y la construcción retrocedió, con los inevitables efectos multiplicadores. De este modo, la economía española no consiguió recuperarse después de 1933, por lo que el paro creció y las huelgas comenzaron.

¿Qué nos parece este enfoque? Tal y como está, la tesis de Hernández Andreu necesita ser reescrita en parte. Lamentablemente, los cuatro últimos capítulos están mal organizados. $\mathrm{El}$ argumento está expuesto tortuosamente, el autor es dado a la repetición, recurre a menudo a la afirmación en lugar de al análisis e ignora las críticas. Adopta, también, una técnica que empieza a ser común entre los historiadores económicos españoles, y que consiste en mezclar lo factual con lo contrafactual. La tesis en sí es un refinamiento de las elaboradas por Román Perpiñá y Albert Balcells, entre otros, a la que ha añadido una dimensión internacional. Hace mucho tiempo que se ha aceptado que, sobre todo después de 1933, el año del acuerdo de Ottawa, las regiones agrícolas exportadoras vieron reducidos sus mercados. En la reelaboración del trabajo de Perpiñá efectuada por Balcells se señala que, a la vez que la prosperidad de las zonas de consumo vitales de la periferia declinó, también lo hicieron las fortunas de la industria textil catalana (Crisis económica y agitación social en Cataluña, 1930-36, 1971). Aunque Juan Hernández Andreu merece nuestro aplauso por ofrecer a los estudiantes universitarios españoles una primera visión de las causas e interpretaciones de la depresión internacional, pienso que ha caído en la trampa de intentar hacer que una España atrasada se ajuste exactamente al modelo general del mundo capitalista avanzado. En el prefacio a los escritos de Perpiñá (De economía crítica, 1930-36, 1982), Jordi Palafox sostiene que la función real del gran economista valenciano, en su momento, fue demostrar a las clases sociales del País Valenciano cómo superar la situación económica de subordinación en la que se encontraban respecto al resto de la Península. Su fracaso pudo haber reflejado las divisiones en la derecha valenciana. No obstante, en un país todavía dominado por los antiguos problemas de una agricultura tradicional, en el que poderosos grupos de interés en los sectores primario y secundario habían conseguido altos niveles de protección arancelaria en el pasado, los problemas recientes de los agricultores independientes, por mucho que éstos hubieran beneficiado a España con sus exportaciones en tiempos mejores, tenían todas las posibilidades de quedar en un segundo plano. Igualmente, las interpretaciones de la historia económica española del período de entreguerras que se centran en su situación son, como mucho, parciales, por muy sofisticadas e ingeniosas que sean.

(Traducción de Angelines Conde Gutiérrez del Alamo.) 